\title{
Medication administration - nursing workload and patient safety in clinical wards
}

\author{
Administração de medicamentos - carga de trabalho de enfermagem e segurança do paciente em \\ unidades clínicas hospitalares \\ Administración de medicamentos - carga de trabajo de enfermería y seguridad del paciente en unidades clínicas
}

Ana Maria Müller de Magalhães',11 ORCID: 0000-0003-0691-7306

Angélica Kreling'

ORCID: 0000-0002-0263-8281

Enaura Helena Brandão Chaves',1,

ORCID: 0000-0001-8841-3624

Simone Silveira Pasin"

ORCID: 0000-0001-5387-8560

Bárbara Motta Castilho' ORCID: 0000-0001-9546-5211

' Universidade Federal do Rio Grande do Sul. Porto Alegre, Rio Grande do Sul, Brazil. "Hospital de Clínicas de Porto Alegre. Porto Alegre, Rio Grande do Sul, Brazil.

How to cite this article: Magalhães AMM, Kreling A, Chaves EHB, Pasin SS, Castilho BM. Medication administration - nursing workload and patient safety in clinical wards. Rev Bras Enferm [Internet]. 2019;72(1):183-9. DOI: http://dx.doi.org/10.1590/0034-7167-2018-0618

Corresponding Author: Ana Maria Müller de Magalhães E-mail: amagalhaes@hcpa.edu.br

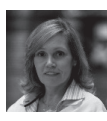

Submission: 08-17-2018

Approval: 11-29-2018

\section{ABSTRACT}

Objective: to analyze the characteristics of the work organization performed by nursing staff regarding medication administration procedures and their implications on the workload of these professionals and on patient safety. Method: the study design is exploratory, with mixed method research and an ecological restorative approach. Data were collected between January 2014 and March 2015, in three inpatient units of a teaching hospital in the south of Brazil, by means of photo walkabout and focus groups, in the qualitative step. In the quantitative phase data were collected from the 162 lists of patients assigned to nursing technicians during their work shifts. Results: the administration of medications has an impact on the professionals' workload and patient safety. Final considerations: there are weaknesses in the process that may contribute to medication administration errors, which are related to the number of doses and the number of patients assigned to each professional.

Descriptors: Medication Systems in the Hospital; Workload; Patient Safety; Nursing; Nursing Care.

\section{RESUMO}

Objetivo: analisar as características da organização do trabalho da equipe de enfermagem quanto aos procedimentos de administração de medicamentos e suas implicações na carga de trabalho desses profissionais e na segurança do paciente. Método: estudo exploratório, com método misto de pesquisa e abordagem restaurativa ecológica. Os dados foram coletados entre janeiro de 2014 e março de 2015, em três unidades de internação de um hospital universitário do sul do Brasil, por meio de caminhada fotográfica (CF) e grupos focais (GF) na etapa qualitativa. $\mathrm{Na}$ fase quantitativa, foram coletados dados das 162 listas de pacientes atribuídos aos técnicos de enfermagem durante seus turnos de trabalho. Resultados: a administração de medicamentos impacta na carga de trabalho dos profissionais e na segurança dos pacientes. Considerações finais: as fragilidades existentes no processo podem contribuir para erros na administração de medicamentos, que estão relacionados com o número de doses e ao número de pacientes atribuídos a cada profissional.

Descritores: Sistemas de Medicação no Hospital; Carga de trabalho; Segurança do Paciente; Enfermagem; Cuidados de Enfermagem.

\section{RESUMEN}

Objetivo: analizar las características de la organización del trabajo real del equipo de enfermería en cuanto a los procedimientos de administración de medicamentos y sus implicaciones en la carga de trabajo de estos profesionales y en la seguridad del paciente. Método: investigación exploratoria con método mixto y enfoque ecológico y restaurativo. Los datos fueron recolectados entre enero de 2014 y marzo de 2015 en tres unidades de internación de un hospital universitario del sur de Brasil, por medio de caminada fotográfica (CF) y grupos focales (GF) en la etapa cualitativa. En la fase cuantitativa, se recogieron datos de las 162 listas de pacientes asignados a los técnicos de enfermería durante sus turnos de trabajo. Resultados: la administración de medicamentos tiene un impacto en la carga de trabajo de los profesionales y en la seguridad del paciente. Consideraciones finales: hay debilidades en el proceso que pueden contribuir a los errores de administración de medicamentos, que están relacionados con el número de dosis y el número de pacientes asignados a cada profesional.

Descriptores: Sistemas de Medicación en el Hospital; Carga de trabajo; Seguridad del Paciente; Enfermería; Cuidados de Enfermería. 


\section{INTRODUCTION}

In the setting of nursing practices, medication-related activities play a key role in achieving an effective therapeutic outcome for patients. In this context, the medication process has been pointed out as one of the prevailing activities at the work shifts of the nursing staff, having an impact on the workload of these professionals ${ }^{(1-2)}$.

The concept of nursing workload adopted in this study corresponds to the amount of time that is spent to meet the care demands of each patient; therefore, it varies according to the degree of patient dependence, which implies hours of care, and the number of patients cared by each professional. The workload measure can be expressed by the ratio of the average number of inpatients in a ward to the average number of professionals per shift in the same ward $^{(3)}$.

Although this is a multidisciplinary process, the nursing staff has a greater share of responsibility and plays a key role in managing pharmacotherapy and ensuring patient safety ${ }^{(4)}$. A study that looked at safety practices in drug administration in clinical wards highlighted advances and positive efforts when the nursing staff employs the "right five" - right patient, right medication, right dose, right route, and right time. However, they concluded that this practice alone is not enough for a safe medication administration, emphasizing the need to strengthen the multidisciplinary teamwork, as well as the knowledge of medication management and pharmacology in the training of nursing students ${ }^{(5)}$.

Despite the advance of new technologies, drug administration remains a complex process related to higher incident rates that can cause adverse events to patients during their hospital stay. Forty per cent of the nursing time in clinical wards is estimated to be associated with drug administration ${ }^{(6)}$, and work overload is a factor that contributes to the occurrence of errors in this process ${ }^{(7)}$.

The whole medication chain process in hospitals includes several steps. Between the arrival and the administration of a single drug, 30 to 40 steps take place, and the possibility of making a mistake increases at each one ${ }^{(8)}$. Considering the Brazilian setting and the context of this study, a few of these steps can be described: computerized physician order entry (CPOE) or handwritten medical prescription, transcription or verification of this prescription, validation by pharmacists, dispensing by the pharmacy in unit doses or batches, automated dispensing system in the ward - is still on a small scale in Brazil - and the preparation and administration of medications by the nursing staff. After administration, the process continues with the monitoring of the medication action and documentation in the patient's health records. Given the scope and relevance of the topic, this study intended to focus on one of the steps of this process and answer the following research questions: What are the characteristics of the nursing staff's work organization related to drug administration procedures in inpatient wards? How does this activity influence the workload of these professionals and patient safety?

\section{OBJECTIVE}

To analyze the characteristics of the work organization performed by nursing staff regarding medication administration procedures and their implications on the workload of these professionals and on patient safety.

\section{METHOD}

\section{Ethical aspects}

The project was submitted and approved by the ethics committee of the institution. All participants were clarified regarding the study objectives and signing the Free and Clarified Consent Term, as recommended by Resolution 466/ 2012 of the National Health Council/MH (Ministry of Health).

To protect the confidentiality of the participants, their speeches were identified with the letter " $\mathrm{P}$ " and a sequential number in accordance with the order of speech in the meetings of the focus group.

\section{Type of study}

This is an exploratory, descriptive and cross-sectional study that uses mixed method research with an ecological restorative approach. According to this approach, participative photographic research methods adapted from the field of ecological restoration are employed ${ }^{(1,9)}$.

The mixed method is a type of research that combines a quantitative and qualitative approach in the same study, so that findings can be complementary. The strategy adopted was that of the exploratory sequential design (QUAL $\rightarrow$ quan), in which qualitative data were collected through focus groups (FG) and photographic walkabout (PW) and quantitative data were subsequently collected to complement and illustrate the initial findings ${ }^{(10)}$.

\section{Methodological procedures}

\section{Study scenario}

The study was conducted in three inpatient wards of a university hospital in the south of Brazil that use an automated dispensing device. In the setting under study, each nurse is responsible, on average, for 15 patients at the morning and afternoon shifts and 22 patients at the night shift. These inpatient units had 45 beds each one and the total of nursing staff were 15 nurses and 39 nursing technicians working in each ward. The patients hospitalized were mainly from internal medicine, neurology and oncology specialties.

It should be noted that, in the Brazilian context, most drugs are prepared and administered by nursing technicians supervised by nurses. By virtue of the law and the complexity of certain medications, nurses are the only ones who are responsible for administering some medications such as chemotherapy, antineoplastics and parenteral nutrition, while the nursing technician performs the nursing care as prescribed by the nurse.

\section{Collection and data organization}

Data were collected between January 2014 and March 2015. The first step included four nurses and 14 nursing technicians 
from a convenience sample comprising those who were invited and accepted to participate in the study. Two focus group were carried out, each one had duration of 90 minutes. Four nurses and seven nursing technicians $(n=11)$ participated in the first focus group (FG1) and the aim was to discuss the medication preparation and administration during the nursing staff work shift in order to prepare the photo walkabout (PW) itinerary. Three research team members and three nursing technicians who participated in the FG1 conducted the PW $(n=6)$ to collect pictures in the study scenario. The PW had duration of 120 minutes. Photos and PW narratives were recorded and organized to prepare the second focus group (FG2). The same four nurses and six nursing technicians $(n=10)$ participated in the $F G 2$ which was based on photo-elicitation process.

In the quantitative step, the 162 lists of patients ${ }^{1}$ assigned to nursing technicians were randomly selected for each shift, totaling 162 lists of patients stratified into 18 lists per shift (morning, afternoon, and night) in each ward. Data were collected from electronic health records (EHR) of patients who were being cared by nursing technicians in each shift.

\section{Data analysis}

The information obtained in the qualitative step was worked on files of the NVivo 10 program, which allowed the organization of different data sources from the transcriptions of FGs recordings and PW narratives, as well as digital photos and field annotations. For the codification of the data was carried out floating reading of the raw material, followed by the analysis, treatment and inference of the results according to the content analysis ${ }^{(11)}$. The categorization was carried out by two researchers, concomitantly, and due to the similarity of the coded themes these were grouped and described in an emerging category.

The integration of the qualitative and quantitative data was planned in the study design, thus the results were presented sequentially and separately at the first moment. The connection and incorporation of both data bases occurred in the data analysis and results discussion. The qualitative analysis defined which quantitative data would be collected to illustrate, complement and confirming some highlighted points by the participants in the first step.

Quantitative data were analyzed using descriptive and analytical statistics.

\section{RESULTS}

The qualitative data were pooled in a category describing "medication administration as organized in the work shift of the nursing staff". The work shift begins with the handoff, when the review checklist for medications prescribed and administered in the previous shift is updated and a summary of the patients' conditions is provided. Once the handoff has ended, the process of dispensing drugs from the automated machines starts.

1 Lists of patients = group of patients assigned to each nursing technicians during their work shifts.
At the time of dispensing, the barcode of each drug is read in accordance with each item in the computerized physician order entry (CPOE). If there is any discrepancy with the prescribed drug when the barcode is read, the device alarm goes off and dispensing stops. Once dispensed, each drug must be identified by a printed self-adhesive label containing patient information (name and medical record), which must be completed manually with drug information.

Professionals report that this process requires attention and focus to avoid errors and is quite time-consuming. The following comments and the pictures in Figure 1 illustrate this issue:

The printed label contains only the patient's name and medical records, we have to write the drug name, the dosage, the patient's bed, so it takes a long time to write everything down if you have 7 or 8 patients. (P10) (FG 1, Jan/28/2014)

I measured it...between taking the prescription and transferring it to the label, it takes around 40 minutes. (P4) (FG2, Jun/27/2014)

The CPOE integrated system and automated dispensing machines allow medications to be dispensed until 2 hours before and 1 hour after the scheduled administration time, a condition required to meet the care and work organization demands of the nursing staff.
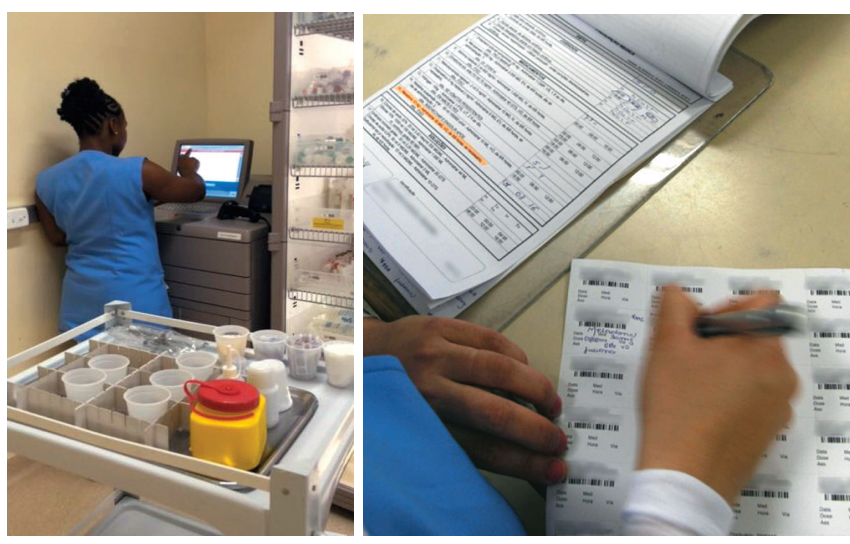

Figure 1 - The drug dispensing and identification process is shown. Photo \#1 - Dispensing drugs from the automated dispensing machine. Photo \#2 - Completing manually the drug information on the label. (Photo Walkabout - PW Jun/03/2014)

Although they recognize drug-related tasks as one of the main demands in their workload, nursing technicians do not know accurately the number of drugs that they prepare and administer per shift. They state that the largest number of drugs to be administered is concentrated at the morning shift and that the average number of patients for whom they take responsibility within their work schedules is 6 or 7 patients per shift.

Medications are prepared in the nurses' station. The tablets are dispensed in unit doses and other medicines are aspirated, reconstituted, diluted, fractionated or crushed by the nursing technician for administration. The medicines are organized in trolleys and carts to be transported to the patient's bedside and administered early in the morning and at other scheduled times. As depicted in the following excerpts and illustrations: 
There is a patient who receives 10 medicine cups, each tablet has to be diluted in a separate cup. (P9) (FG 1 - Jan/28/2014)

The morning time is the one that has more medications...these new dividers slide, and then a mix-up and a mistake may occur at the time of administration. (P11) (FG 1 - Jan/28/2014)

Focus group participants report that, while they are preparing medications, they are constantly disrupted by requests from family members, patients, and other staff that interfere with the process and lead to delays in medication schedules. In addition, there are other work demands to be addressed, such as complications with patients and other nursing procedures (bath, hygiene, and dressings). According to participants, these disruptions cause task discontinuity, distraction and possibility of errors, as reported in the following excerpts and in the pictures in Figure 2:

It's a very complex process, you go on duty, then you go see the patient, later you prepare and administer the medicine, and then there's the bath, diaper change...there are lot of things to do. (P11) (FG 1 Jan/28/2014)

We have a lot of tasks. You go with that tray with several medicines, sometimes you end up mistaking a patient or medication for another, because there's a lot to do at the same time. (P5) (FG 2 Jun/27/2014)
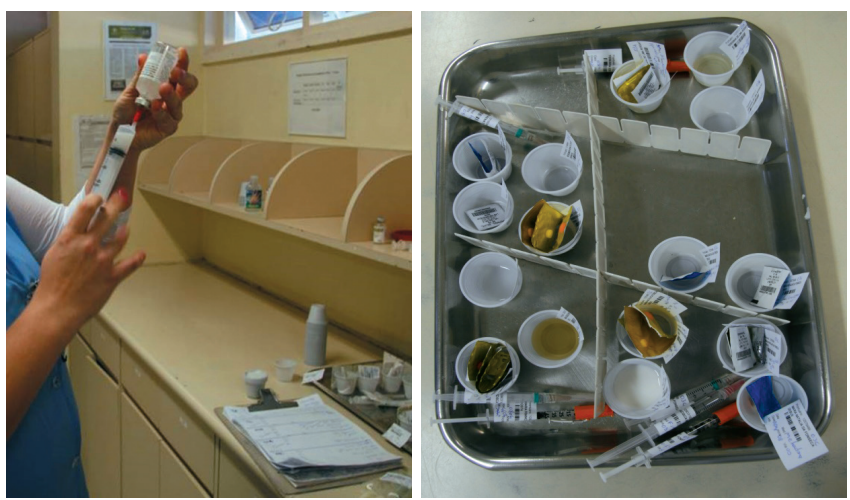

Figure 2 - Pictures showing the drug preparation and reconstitution process in the nurse's station and the medicines organized on a tray to be taken in a cart to the bedside. Photo \#3- Reconstitution of an intravenous medication. Photo \#4 - Tray with medications to be administered by a nursing technician to patients in his/her work schedule. (Photo Walkabout - PW Jun/03/2014)

Even with an CPOE, there were inaccuracies and flaws regarding prescribed medication items, such as medication duplicity and lack of clarity in excluding items from the prescription, which may contribute to the occurrence of adverse events. In addition, it was found that drug administration needed to be recorded manually, with agreed-upon symbols, such as a dash for those actually administered and a circle for those that could not be administered. These issues can be seen in the figures below, Figure 3.

Focus group participants reported that, at times, "system" problems occurred, leading to the duplication of items in the CPOE. Furthermore, they commented that the inclusion and exclusion of drug items is not adequately highlighted, which
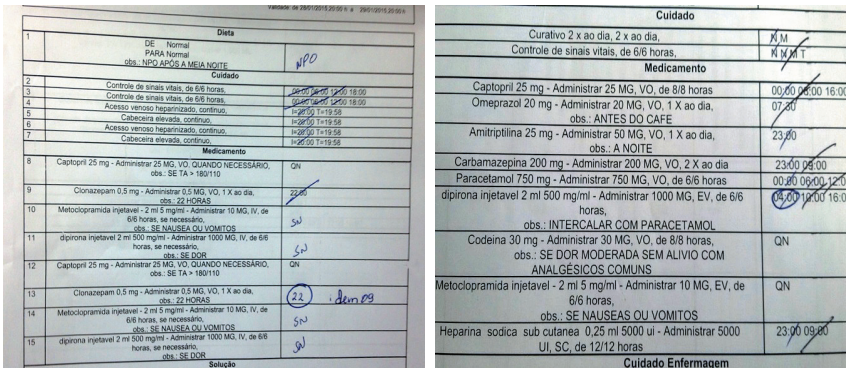

Figure 3 - Printed electronic prescriptions and manual check performed by the nursing technicians. Photo \# 5 - Medication items 8 and 12,9 and 13, 10 and 14, 11 and 15 repeated in a CPOE. Photo \# 6 - Medication item marked with a circle and a dash, raising doubts about its administration

may lead to failures when checking the drugs to be administered. Another issue stressed by participants is the lack of communication with the medical staff, as there are no alarms or warnings about CPOE changes or transfers. Therefore, if there is no verbal communication about the changes required by the medical staff, the nursing staff will only learn of the changes at the time they access a computer, which may take place after the time that was previously stipulated for drug administration.

There were 1,148 admissions during the period of quantitative data collection, between December 2014 and March 2015, in which 581 (50.61\%) patients were males, 561 (48.87\%) were 60 years old or older, 325 (22.20\%) suffered from circulatory system disorders, $316(21.58 \%)$ had neoplasms and $135(9.22 \%)$ digestive tract diseases, among others. Based on 162 patient lists of the nursing technicians, we found an average number of $5.98(\mathrm{SD}=0.90)$ patients assigned to a nursing technician in the morning shift, 5.98 ( $S D=0.83$ ) in the afternoon shift and $7.44(\mathrm{SD}=0.60)$ in the night shift. A total of 1048 CPOE were evaluated, which sometimes were for the same patients, according to a draw.

The data indicated that, on average, 60.45 (SD = 20.26) drug doses per shift and $9.26(S D=2.46)$ doses per patient were prescribed to be administered by each nursing technician, according to the patient's conditions. As for the number of medications administered, a mean of $34.5(S D=15.64)$ per shift/nursing technician was identified, 35.43 ( $S D=11.17$ ) in the morning shift, 20.20 (SD $=7.76)$ in the afternoon shift, and $47.87(S D=12.85)$ in the night shift. The mean number of doses administered per patient was $5.23(\mathrm{SD}=2.00), 5.92(\mathrm{SD}=1.70)$ in the morning shift, $3.37(\mathrm{SD}=$ 1.13 ) in the afternoon shift and $6.41(S D=1.58)$ in the night shift. Using the Bonferroni adjustment test for comparison, the number of doses administered showed a significant difference between the three shifts, and the afternoon shift presented a significantly lower difference when compared with the others $(p<0.05)$.

Sixteen different types of routes of drug administration were identified, with predominance of oral medications, 67.97 (SD = 13.62 ) in the morning shift, $57.99(S D=15.78)$ in the afternoon shift, and 73.04 ( $S D=13.42$ ) in the night shift. The intravenous route was the second most frequently used type, followed by subcutaneous administration. The other routes of drug administration were intramuscular, nasogastric tube, topical, inhalation, serotherapy, ocular, rectal, sublingual, auricular, nasal, genitourinary, intradermal and epidural. 


\section{DISCUSSION}

The analysis of the work organization performed by nursing staff regarding medication administration procedures during the shift demonstrates that the procedures related to patients under pharmacotherapy are complex and have an impact both on the nursing workload and on the patient safety. The information from discussions in the focus groups and from the photo walkabout indicates that the high workload, defined by the number of treated patients and activities to be performed, associated with distractions, interruptions and adverse events, interferes with the safe process of medication administration.

Since the beginning of the work shift - with the handoff - drug information takes on a key role in organizing work and is vital to the continuance of care and an effective therapy. However, weaknesses and potential flaws in this process are noted due to the large number of drugs and nursing procedures to be performed with patients in a work shift, leading to constant disruptions at the time of drug preparation and administration. These findings are supported by a number of studies indicating that work overload, which results in the hasty performance of tasks, stress and diminished attention, and distractions are among the main risk factors for the administration of wrong drugs ${ }^{(12-15)}$.

The demands and tasks required for administering drugs comprise several stages that are subject to failures, which are multifactorial (human-dependent and/or systemic). The ability of attention and concentration, as well as knowledge of medicines, are essential conditions for professionals to carry out this process. On the other hand, the number of patients being treated and the number of drugs to be administered, as well as the facilities and equipment available to perform this procedure are systemic factors that can interfere with the dynamics of a safe process of drug administration. Studies point out work overload, distractions and inefficient communication as the main causes for the occurrence of drug administration errors and note that focus is imperative for this task, with suitable time and space being necessary for managing medications without unnecessary disruptions ${ }^{(16-17)}$.

The participants pointed out that errors may occur due to the large number of drugs on a tray, and medications or patients may be mistaken for others. There are guidelines and protocols at the institution that advocate visually comparing the drug name to the patient identification bracelet, as there is no barcode-assisted medication administration system yet at the bedside for this comparison and for electronic checks of the drug administered, which could bring greater safety to the process.

Studies indicate that errors occur at the ratio of one to four drugs administered and that the increase in the number of patients assigned to a nurse, the increase in the number of doses, the diversity and the form of drug presentation - especially when administered together - are among the main causal factors for errors $^{(18-20)}$. The organizational structure of the nursing staff under study establishes the joint administration of drugs to patients that are assigned to each professional, as evidenced by the trays carried to the bedside.

Even with the use of automated dispensing systems to enhance the safety of the medication process in the wards, it turns out that there are still several steps that must be performed manually, such as filling out drug identification labels, reviewing, adjusting and scheduling administration times in CPOE, in addition to checking whether the drugs administered correspond to those in printed medical prescriptions. Communication failures were identified in those documents, such as duplicity of agreed-upon symbols to confirm or not the administration of a given drug at the prescribed time. In addition, failures were identified in the CPOE, such as duplicity of drugs in the same prescription and lack of signaling for the exclusion or inclusion of drugs, which shows that a computerized prescription does not ensure a safe process and can lead to errors and confuse the professionals who prepare and administer medications. It should be noted that drug duplication in the CPOE occurred when there was more than one prescription timetable, and since 2015, with the unification of schedules, this error has been corrected, demonstrating the commitment of the institution to identifying and proposing improvements to this process.

Despite considering that medications are an important factor to work overload, the nursing professionals do not know the mean number of drugs that they administer in each work shift. A divergence was observed between "real" and "imaginary" work, because the participants, in the qualitative phase, stated that the morning shift had a greater number of drugs to be administered, but it was found, in the quantitative phase, that the greatest number of drugs administered was in the night shift, with 47.87 $(S D=12.85)$ medications administered by each nursing technician. It is important to emphasize that, during the night shift, nursing technicians have a larger number of patients in their patient lists and work for 12 hours, different from the six hours worked in each daytime shift.

Another noteworthy finding is that only $57 \%$ of prescribed drugs were actually administered to patients by nursing technicians. Thus, better criteria and standardizations are observed to be necessary for planning medical prescriptions, avoiding unnecessary items whose localization in an extensive list puts a heavier burden of work on the nursing staff.

The high number of medications prepared and administered by nursing technicians in each shift was confirmed by FG discussions and photos obtained in qualitative data as well as by the numbers founded in quantitative data with a mean of 34.5 (SD $=15.64)$ medications per shift and a mean of $47.87(\mathrm{SD}=12.85)$ medications in the night shift. The amount of information regarding number of items in the medical prescription, manual and electronic records, large number and diversity of drugs or doses were evidenced in both arms of data collection by the testimonials of participants, photos and numbers presented in the study. These data sources may contribute to better knowledge of the nursing staff about medication preparation and administration in their work shift routine. In addition, many circumstances and risk factors for errors in these steps of medication process were identified by the nursing team as well as very aspects related to nursing workload.

\section{Study limitations}

This is a single-center, cross-sectional study; therefore, generalizations are not possible. It should be considered that in other 
settings, such as pediatric or intensive care units, work demands arising from the care of patients under pharmacotherapy may be different and, possibly, present other results.

\section{Contributions to the Nursing}

It should be noted that the findings in this study provide relevant information for discussing safety in medication administration processes and the workload of the nursing staff in the Brazilian healthcare context. The photos and the discussion in focus groups enrich the understanding of the way the staff is organized in order to administer medications, allowing the identification of weak spots and opportunities to improve this process. Describing and identifying the number of medications administered by a nursing professional, as well as the number of treated patients, helps to understand how the staff organizes itself to handle patient care demands and how the medication process requires time, knowledge and attention on the part of health professionals, being emphasized as an activity that is central to their work shift.

\section{FINAL CONSIDERATIONS}

When the organizational characteristics of the nursing staff's work regarding medication administration procedures were analyzed, it was confirmed that this is a prevailing activity in the nursing care provided for patients. This can be seen both in the qualitative data, through the discussions from the focus groups, the participants'testimonials and the photos of the study site, and in the quantitative data, through the number of medications administered per shift by each nursing technician and the number of patients in their patient lists.

The findings point out that drug administration is a task that has an impact both on the nursing staff's workload and on patient safety in an intrinsically related way. Drug management involves a multidisciplinary team and the errors arising from this process can occur at any stage - prescribing, dispensing and administration - with the nursing staff being the last barrier to identify and intercept them before they reach the patient.

Failures in the medication process may be human-dependent, resulting from distractions, disruptions, lack of attention, fatigue and stress of professionals, as well as systemic, resulting from inadequate workplace conditions, lack of personnel, diversity of types and routes of drug administration, limited knowledge and staff training.

The number of inpatients and their clinical conditions, increasingly more severe and with several comorbidities, imply increasing the doses of prescribed and administered drugs, resulting in an increased work demand. The drug administration, workload and patient safety triad was found to be a cyclical relationship, in which the increased number of patients in the work schedules of nursing technicians increases the number of drugs to be administered and the chances for the occurrence of adverse events.

The results allow us to assert that detailing the care process in the management of drug administration can give visibility to this activity in the organization of the nursing staff's work, contributing to identifying possible risks to patient safety. A careful look at this process also allows us to point out measures to prevent errors, such as prescribing medications more accurately and only those that are strictly necessary for the patient's treatment, using the automated dispensing systems, effective communication among professionals, fighting against the occurrence of distractions and interruptions, and using the "five rights" when preparing and administering medications.

\section{AKNOWLEDGEMENTS}

We would like to thank the Universidade Federal do Rio Grande do Sul (UFRGS) - PROPESQ, the Post-graduate Program in Nursing-PPGENF - Nursing School - and the Research Incentive Fund- FIPE - Hospital de Clínicas de Porto Alegre - HCPA.

\section{REFERENCES}

1. Magalhães AMM, Dall'Agnol CM, Marck PB. Nursing workload and patient safety - a mixed method study with an ecological restorative approach. Rev Lat Am Enfermagem [Internet]. 2013 [cited 2018 Jul 08];21(spe):146-54. Available from: http://dx.doi.org/10.1590/ S0104-11692013000700019

2. Magalhães AMM, Moura GMSS, Pasin SS, Funcke LB, Pardal BM, Kreling A. The medication process, workload and patient safety in inpatients units. Rev Esc Enferm USP [Internet]. 2015 [cited 2018 Jul 08];49(spe):43-50. Available from: http://dx.doi.org/10.1590/ S0080-623420150000700007

3. Magalhães AMM, Costa DG, Riboldi CO, Mergen T, Barbosa AS, Moura GMSS. Association between workload of the nursing staff and patient safety outcomes. Rev Esc Enferm USP [Internet]. 2017 [cited 2018 Jul 15];51:e03255. Available from: http://dx.doi.org/10.1590/ s1980-220x2016021203255

4. Bourbonnais FF, Caswell W. Teaching successful medication administration today: more than just knowing your 'rights'. Nurse Educ Pract [Internet]. 2014 [cited 2018 Jul 08];14(4):391-5. Available from: https://doi.org/10.1016/j.nepr.2014.03.003

5. Adhikari R, Tocher J, Smith P, Corcoran J, MacArthur J. A multi-disciplinary approach to medication safety and the implication for nursing education and practice. Nurse Educ Today [Internet]. 2014 [cited 2018 Jul 08];34(2):185-90. Available from: https://doi.org/10.1016/j. nedt.2013.10.008

6. Armitage G, Knapman H. Adverse events in drug administration: a literature review. J Nurs Manag [Internet]. 2003 [cited 2018 Dec 27];11(2):130-40. Available from: https://doi.org/10.1046/j.1365-2834.2003.00359.x

7. Volpe CRG, Pinho DLM, Stival MM, Karnikowski MGO. Medication errors in a public hospital in Brazil. Br J Nurs [Internet]. 2014 [cited 2018 Jul 08];23(11):552-9. Available from: https://doi.org/10.12968/bjon.2014.23.11.552 
8. Levine S, Cohen MR. Preventing medication errors in pediatric and neonatal patients. In: Cohen MR, editor. Medication errors. 2 ed. Washington (DC): American Pharmacists Association; 2007. p. 469-92.

9. Gimenes FRE, Marck PB, Atila EG, Cassini SHB. Engaging nurses to strengthen medication safety: fostering and capturing change with restorative photographic research methods. Int J Nurs Pract [Internet]. 2015 [cited 2018 Jul 15];21(6):741-8. Available from: https://doi. org/10.1111/ijn.12304

10. Guetterman TC. Designing a rigorous mixed methods research study. J Qual Res [Internet]. 2017 [cited 2018 Dec 27];18(1):1-16. Available from: http://www.dbpia.co.kr/Journal/ArticleDetail/NODE07183460

11. Minayo MCS. O desafio do conhecimento: pesquisa qualitativa em saúde. 14nd ed. São Paulo: Hucitec; 2014. 406 p.

12. Camerini FG, Colcher AP, Moraes DS, Souza DL, Vasconcelos JR, Neves RO. Risk factors for the occurrence of errors in the preparation of intravenous medications: an integrative review. Cogitare Enferm [Internet]. 2014 [cited 2018 Jul 15];19(2):368-74. Available from: http:// dx.doi.org/10.5380/ce.v19i2.37362

13. Tirgar A, Ahmadi MH, Jafarpour HA, Samaei SE. Effective factors on occurrence of drugs mistakes from the viewpoints of nurses. AOH [Internet]. 2018 [cited 2018 Oct 22];2(1):48-55. Available from: http://aoh.ssu.ac.ir/article-1-55-en.pdf

14. Forte ECN, Pires DEP, Padilha MI, Martins MMFPS. Nursing errors: a study of the current literature. Texto Contexto Enferm [Internet]. 2017 [cited 2018 Jul 15];26(2):e01400016. Available from: http://dx.doi.org/10.1590/0104-07072017001400016

15. Fathi A, Hajizadeh M, Moradi K, Zandian H, Dezhkameh M, Kazemzadeh S, et al. Medication errors among nurses in teaching hospitals in the west of Iran: what we need to know about prevalence, types, and barriers to reporting. Epidemiol Health [Internet]. 2017 [cited 2018 Jul 15];39:e2017022. Available from: https://doi.org/10.4178/epih.e2017022

16. Härkänen M, Turunen H, Saano S, Vehviläinen-Julkunen K. Detecting medication errors: analysis based on a hospital's incident reports. Int J Nurs Pract [Internet]. 2015 [cited 2018 Jul 15];21(2):141-6. Available from: https://doi.org/10.1111/ijn.12227

17. Sears K, O'Brien-Pallas L, Stevens B, Murphy GT. The relationship between the nursing work environment and the occurrence of reported paediatric medication administration errors: a pan canadian study. J Pediatr Nurs [Internet]. 2013 [cited 2018 Jul 15];28(4):351-6. Available from: https://www.pediatricnursing.org/article/S0882-5963(12)00329-6/fulltext

18. Härkänen M, Blignaut A, Vehviläinen-Julkunen K. Focus group discussions of registered nurses' perceptions of challenges in the medication administration process. Nurs Health Sci [Internet]. 2018 [cited 2018 Oct 22];20(4):431-7. Available from: https://doi.org/10.1111/nhs.12432

19. Paranaguá TTB, Bezerra ALQ, Santos ALM, Silva AEBC. Prevalence and factors associated with incidents related to medication in surgical patients. Rev Esc Enferm USP [Internet]. 2014 [cited 2018 Jul 15];48(1):41-7 Available from: http://dx.doi.org/10.1590/ S0080-623420140000100005

20. Härkänen $\mathrm{M}$, Ahonen J, Kervinen $\mathrm{M}$, Turunen $\mathrm{H}$, Vehviläinen-Julkunen $\mathrm{K}$. The factors associated with medication errors in adult medical and surgical inpatients: a direct observation approach with medication record reviews. Scand J Caring Sci [Internet]. 2015 [cited 2018 Jul 15];29(2):297-306. Available from: https://doi.org/10.1111/scs.12163 